\title{
A PILOT STUDY OF TOPIRAMATE IN CHILDREN WITH LENNOX-GASTAUT SYNDROME
}

\author{
MARILISA M. GUERREIRO*, MARIA LUIZA G. MANREZA**, ANNA ELISA SCOTONI*, E.A. SILVA*, \\ CARLOS A. M. GUERREIRO*, E.A.P. SOUZA*, V.B. FERREIRA**, UMBERTINA C. REED**, ARON \\ DIAMENT**, R. TREFIGLIO ${ }^{* * *}$, H.C. CHIU ${ }^{* * *}$, J. BACALTCHUK ${ }^{* * *}$
}

\begin{abstract}
We conducted an open, add-on study with topiramate (TPM) as adjunctive therapy in LennoxGastaut syndrome (LGS), to assess the long-term efficacy and safety and to evaluate quality of life (QL) measurements in the chronic use of TPM. We studied 19 patients (11 male; age ranging from 4 to 14 years) with uncontrolled seizures receiving 2-3 anti-epileptic drugs. Patients were followed up to 36 months of treatment. A questionnaire was used to query parents about QL. Seven patients completed the study at 36 months and seizure frequency was reduced $\geq 75 \%$ in 4 , and $<50 \%$ in 3 patients. Two children became seizure free for more than 24 months. Most side effects were CNS related, with the most frequent being somnolence and anorexia. These were generally transient. One patient dropped-out due to powder in the urine. None of the patients required hospitalization. At 36 months, patients' alertness (2/7), interaction with environment (5/7), ability to perform daily activities (5/7), and verbal performance (6/7) improved on TPM. We conclude that TPM may be useful as adjunctive therapy in the treatment of LGS. The efficacy of TPM was maintained in long-term treatment in more than $40 \%$ of patients, long term safety was confirmed and QL improved on TPM.
\end{abstract}

KEY WORDS: Lennox-Gastaut syndrome, topiramate, epilepsy treatment.

\section{Estudo piloto com topiramato em crianças com síndrome de Lennox-Gastaut}

RESUMO - Realizamos estudo aberto, de adição do topiramato (TPM) como medicação adjuvante no tratamento da síndrome de Lennox-Gastaut (SLG), com a finalidade de verificar a eficácia e a segurança de avaliar a qualidade de vida (QV) no uso crônico do TPM. Estudamos 19 pacientes (11 do sexo masculino; idade entre 4 e 14 anos) com epilepsia de difícil controle e em uso de 2 a 3 drogas anti-epilépticas. Os pacientes foram seguidos por 36 meses. Um questionário foi aplicado aos pais para se avaliar QV. Sete crianças completaram o estudo. A frequência de crises foi reduzida em mais de $75 \%$ em 4 e em menos de $50 \%$ em 3 delas. Dois pacientes ficaram sem crises. A maioria dos efeitos colaterais relacionou-se ao sistema nervoso central, sendo sonolência e anorexia os mais frequentes e transitórios. Um paciente foi excluído do estudo por apresentar pó na urina. Nenhuma criança necessitou de hospitalização. Aos 36 meses, os pacientes encontravam-se mais alertas (2/7), e houve melhora na interação com o meio ambiente (5/7), na habilidade em realizar tarefas diárias (5/7) e na performance verbal (6/ 7). Concluímos que o TPM pode ser útil como terapia adjuvante na SLG. A eficácia manteve-se no tratamento a longo prazo em mais de $40 \%$ dos pacientes, a segurança foi confirmada e a QV melhorou com o uso do TPM.

Palavras-chave: síndrome de Lennox-Gastaut, topiramato, tratamento de epilepsia.

Topiramate (TPM), a novel antiepileptic drug (AED), has multiple mechanisms of action ${ }^{1,2}$ suggesting that it may be useful in a broad spectrum of seizure types, including those usually present in Lennox-Gastaut syndrome (LGS).

*Departamento de Neurologia, Faculdade de Ciência Médica (FCM), Universidade Estadual de Campinas (UNICAMP); **Divisão de Clínica Neurológica do Hospital das Clínicas da Faculdade de Medicina da Universidade de São Paulo, ***Janssen-Cilag Brazil. Supported by a grant from the R.W. Johnson Pharmaceutical Research Institute. Presented in part at the $49^{\text {th }}$ Annual Meeting of the American Academy of Neurology. Aceite: 25-novembro-1998.

Dra. Marilisa M. Guerreiro - Departamento de Neurologia, FCM, UNICAMP - Cx. Postal 6111 - 13081-970 Campinas SP - Brasil. 
To date, there is no satisfactory and efficacious treatment available for LGS. Epilepsy surgery may lead to improvement in some patients but it usually does not eliminate all seizures ${ }^{3}$. Felbamate has been approved for the treatment of LGS in the United States, although the incidence of rare but serious effects of aplastic anemia and liver failure has limited its usefulness ${ }^{4,5}$. Finding the best treatment for LGS is still a challenge. The current drug treatment of this syndrome usually requires polypharmacy. Therefore, AED interaction is always a concern in the management of such patients. Choosing drugs with the least possible interaction potential is a reasonable goal. Previous studies with $\mathrm{TPM}^{6-8}$ have shown that there were no major interactions during coadministration with standard AEDs.

TPM demonstrates most of the pharmacokinetic properties considered ideal for an AED ${ }^{9}$, such as fast and complete absorption, linear pharmacokinetics, predominantly renal elimination as mainly an intact drug, low level of plasma protein binding, minimal interaction with other AEDs and long half-life. On the basis of those findings and the multiple mechanisms of action of TPM we considered that this could be a new good option in the treatment of LGS.

In order to investigate this hypothesis a protocol was designed which aimed to evaluate the efficacy and safety of TPM as adjunctive therapy in LGS. An extension phase was designed in order to assess the long-term efficacy and safety of TPM. We also intended to evaluate quality of life (QL) measurements in the chronic use of TPM.

\section{METHOD}

\section{Subject Population}

We studied 19 patients with LGS: 11 male and 8 female with age ranging from 4 to 14 years. LGS was defined by multiple seizure types, including atypical absence and drop attacks, slow spike wave EEG patterns with abnormal background activity, mental retardation and resistance to standard AEDs ${ }^{10,11}$. Patients had uncontrolled seizures and were receiving 2 to 3 AEDs. Five of our patients were not presenting drop-attacks at the time of the enrollment but they have had such seizures in other period of their lives and the EEG was still consistent with LGS. In this syndrome, drop-attacks can usually be seen at some time in the course of the affection and may modify with the evolution ${ }^{11,12}$.

Demographic data, seizure types, etiology and medications at baseline are presented in Table 1. All patients had had previous computed tomographic or magnetic resonance evaluations. Children were recruited from 2 different centers.

Exclusion criteria carefully eliminated subjects with progressive neurological disorders, correctable cause of their seizures, significant history of other diseases, anoxic episodes within the past year, inadequate parent/ guardian supervision, and history of a psychiatric disorder. Subjects on ketogenic diets or who have received ACTH or Acetazolamide within the last six months were also excluded.

The institutional review board approved the protocol and informed consent was obtained prior to performing trial related procedures from parents or guardians.

Study Design

There were four phases of this study: baseline period, titration (visits 1 to 4), stabilization (visits 5 and 6 ) and extension (from visit 7 on). The baseline phase lasted one month and was designed to perform clinical and laboratory evaluation covering medical history, seizure counting based on diary, laboratory tests (including hematology, biochemistry, liver function, kidney function and pregnancy testing for childbearing potential girls), electrocardiogram, electroencephalogram and dosage of AEDs other than TPM.

Titration phase: this phase consisted of TPM dose escalation from $1 \mathrm{mg} / \mathrm{kg} /$ day to $9 \mathrm{mg} / \mathrm{kg} /$ day (maximum $800 \mathrm{mg} /$ day) over 4 weeks. The trial medication was gradually increased and adjusted every week during a 4week period according to the clinical response. A fixed titration schedule was used: $1,3,6,9 \mathrm{mg} / \mathrm{kg} / \mathrm{day}$ in the first, second, third and fourth week subsequently. The schedule could be interrupted if maximum tolerated dose would be achieved. Patients were assessed every week.

The stabilization phase lasted 4 weeks when patients were maintained on stable TPM and concomitant AED doses. Patients were assessed twice during this phase, every 14 days.

Extension phase: during this phase AED dosing could be changed according to clinical effects. Monotherapy with TPM also could be tried during this phase. Patients were assessed every month for the first 3 months of this phase (visits 7, 8 and 9). Thereafter, visits occurred every 3 months, unless medically indicated. 
Table 1. Summary of clinical and demographic data.

\begin{tabular}{|c|c|c|c|c|c|c|c|c|}
\hline Patient & Gender & $\begin{array}{c}\text { Date } \\
\text { visit } 1\end{array}$ & $\begin{array}{l}\text { Birth } A \\
\text { date }\end{array}$ & $\begin{array}{l}\text { Age at TPM } \\
\text { therapy }\end{array}$ & $\begin{array}{l}\text { Seizure } \\
\text { types }\end{array}$ & $\begin{array}{c}\text { Age at } \\
\text { seizure onset }\end{array}$ & $\begin{array}{l}\text { Etiology/ } \\
\text { Imaging }\end{array}$ & $\begin{array}{l}\text { AEDs at } \\
\text { TPM onset }\end{array}$ \\
\hline 1 & $\mathrm{~F}$ & 06/07/94 & $22 / 10 / 81$ & 12,9 & $\mathrm{TC}, \mathrm{My}, \mathrm{T}$ & $3 \mathrm{~m}, 4 \mathrm{y} 5 \mathrm{~m}, 4 \mathrm{y} 7 \mathrm{~m}$ & Microcephaly & $\begin{array}{c}\text { CLB/VPA/ } \\
\text { CBZ }\end{array}$ \\
\hline 2 & M & 06/07/94 & $31 / 01 / 82$ & 12,6 & T, TC, My, AA & $3 \mathrm{~m}, 3 \mathrm{~m}, 4 \mathrm{y}, 5 \mathrm{y}$ & Unknown & VPA/NTZ \\
\hline 3 & M & $06 / 07 / 94$ & $29 / 06 / 81$ & 13,2 & CP, At, My, AA & $7 y, 8 y, 9 y, 11 y$ & Unknown & $\begin{array}{l}\text { CBZ/VPA/ } \\
\text { PHB }\end{array}$ \\
\hline 4 & $\mathrm{~F}$ & 03/08/94 & $20 / 11 / 84$ & 9,8 & $\mathrm{~T}, \mathrm{At}, \mathrm{CP}$ & 3m, NA, NA & Unknown & $\begin{array}{c}\text { VGB/CBZ/ } \\
\text { NTZ }\end{array}$ \\
\hline 5 & M & $14 / 09 / 94$ & $16 / 02 / 80$ & 14,8 & TC, AA, My & $9 y, 9.5 y, 11.5 y$ & $\begin{array}{l}\text { Ventricular } \\
\text { asymmetry }\end{array}$ & $\begin{array}{l}\text { VPA/CBZ/ } \\
\text { ETX }\end{array}$ \\
\hline 6 & $\mathrm{~F}$ & $24 / 08 / 94$ & $13 / 08 / 90$ & 5,1 & TC, At, My, PE & $4 y, 3 y, 3 y, 3 y$ & Unknown & ETX/NTZ \\
\hline 7 & $\mathrm{~F}$ & $14 / 09 / 94$ & $14 / 03 / 86$ & 8,6 & IS, CP, T, My & $5 \mathrm{~m}, 2 \mathrm{y}, 3 \mathrm{y}, 7 \mathrm{y}$ & $\begin{array}{c}\text { Aicardi } \\
\text { syndrome }\end{array}$ & CBZ/VPA \\
\hline 8 & M & $23 / 11 / 94$ & $16 / 08 / 82$ & 12,5 & TC, C, My, T & $8 \mathrm{y}, 2 \mathrm{~m}, 3.5 \mathrm{y}, 2 \mathrm{~m}$ & Unknown & $\mathrm{VGB} / \mathrm{CBZ}$ \\
\hline 9 & F & $08 / 02 / 95$ & $18 / 08 / 84$ & 10,6 & My, T, At, CP & $5 \mathrm{~m}, 4 \mathrm{y}, 4 \mathrm{y}, 4 \mathrm{y}$ & Unknown & CBZ/CLB \\
\hline 10 & M & $11 / 02 / 94$ & $10 / 04 / 85$ & 9,0 & At, AA & $9 m, 9 m$ & PI Infarction & DPH/CLB \\
\hline 11 & M & $11 / 02 / 94$ & $20 / 10 / 85$ & 8,4 & At, CP, TC & $6 \mathrm{~m}, 6 \mathrm{~m}, 6 \mathrm{~m}$ & Calc.LOR & $\mathrm{CBZ} / \mathrm{PHB}$ \\
\hline 12 & M & $11 / 02 / 94$ & 07/01/90 & 4,2 & At, My, TC & $2 y, 2 y, 1 y$ & Aracnoid cyst & VPA/CLB \\
\hline 13 & $\mathrm{~F}$ & $11 / 03 / 94$ & $24 / 09 / 81$ & 12,6 & AA, TC, At & $4 y, 4 y, 4 y$ & $\begin{array}{c}\text { Encephalic } \\
\text { trauma }\end{array}$ & PHB/DPH \\
\hline 14 & M & $15 / 04 / 94$ & $24 / 10 / 85$ & 8,6 & $\begin{array}{l}\text { At, T, AA, } \\
\text { SP, TC }\end{array}$ & $4 y, 4 y, 4 y, 4 y, 4 y$ & $\begin{array}{c}\text { Porencephalic } \\
\text { cyst }\end{array}$ & VPA/NTZ \\
\hline 15 & M & $10 / 06 / 94$ & 03/03/90 & 4,3 & My, At, AA & $1 \mathrm{~m}, 3 \mathrm{~m}, 3 \mathrm{y}$ & Unknown & VPA/DZP \\
\hline 16 & M & $24 / 06 / 94$ & $01 / 01 / 90$ & 4,5 & At, My, AA & $18 \mathrm{~m}, 18 \mathrm{~m}, 18 \mathrm{~m}$ & $\begin{array}{l}\text { Cerebral } \\
\text { atrophy }\end{array}$ & VPA/CLZ \\
\hline 17 & $\mathrm{~F}$ & $12 / 08 / 94$ & $26 / 05 / 87$ & 7,3 & At, T, My, TC & $18 \mathrm{~m}, 6 \mathrm{y}, 4 \mathrm{~m}, 6 \mathrm{y}$ & Unknown & VPA/CLB \\
\hline 18 & M & $28 / 10 / 94$ & $25 / 11 / 81$ & 13,1 & At, AA & NA & $\begin{array}{l}\text { Cerebral } \\
\text { atrophy }\end{array}$ & VPA/CLZ \\
\hline 19 & M & $28 / 11 / 94$ & $05 / 07 / 80$ & 14,6 & At, T, TC & $11 y, 13 y, 2 y$ & Unknown & CBZ/CLZ \\
\hline
\end{tabular}

Gender: F, female; M, male.

Seizure types: TC, tonic-clonic seizure; My, myoclonic seizure; T, tonic seizure; AA, atypical absence; CP, complex partial seizure; At, atonic seizure; PE, partial evolving to secondarily generalized seizure; IS, infantile spasm; SP, simple partial seizure.

Age at seizure onset: m, months; y, years; NA, data not available.

Etiology / Imaging: PI, perinatal ischemic; Calc. LOR, calcifications on the left occipital region.

AEDs at TPM onset: AEDs, antiepileptic drugs; TPM, topiramate; CLB, clobazam; VPA, valproate; CBZ, carbamazepine; NTZ, nitrazepam; PHB, phenobarbital; VGB, vigabatrin; ETX, etosuximide; DPH, phenytoin; DPZ, diazepam; CLZ, clonazepam. 
Starting with visit 1 , the follow-up period was 36 months.

TPM was supplied as $25 \mathrm{mg}, 50 \mathrm{mg}$, and $100 \mathrm{mg}$ in bottles of 60 tablets provided by the R.W. Johnson PRI. The daily dosage was divided in 2 intakes.

Information was obtained through patient diaries about seizure frequency and seizure type. A questionnaire was used to query parents about patients' alertness, ability to perform daily activities, interaction with environment and verbal response. Parents or guardians were asked to inform if patients got better or worse, always comparing their appreciation with baseline evaluation. The answers were graduated according to the following: 1 , very much improved; 2 , much improved; 3 , improved; 4 , no change; 5 , worse; 6 , much worse; 7 , very much worse. The measurements of QL were made at visit 1 and at 3, 6, 12, 24 and 36 months.

The safety of study medication was evaluated on the basis of adverse events collected at each study visit. Physical and neurological examinations, measurement of vital signs and body weight, collection and counting of unused TPM tablets, laboratory exams (hematology, serum chemistry, urinalysis), reviewed patient diary and questionnaire assessment were recorded at every visit. ECG recordings were performed before and at the middle of the treatment.

Subjects were withdrawn from the study for any of the following reasons: subject choice to discontinue the study, significant protocol violation, severe adverse experience (if hospitalization due to the treatment was required or if there was a significant interference with the life of the patient), development of intercurrent illness which would put the subject at increased risk or invalidate the results of the study, worsening of seizures, and lack of efficacy.

\section{RESULTS}

Table 2 shows the overall outcome of the patients.

\section{Drop-outs}

No patient discontinued treatment during titration phase. Two patients (Cases 18 and 19) dropped-out during stabilization phase: one (Case 18) because of significant protocol violation -

Table 2. Overall outcome of patients treated with TPM throughout follow-up.

\begin{tabular}{cccccccc}
\hline Patient & F-up $<3 \mathrm{~m}$ & F-up 3m & F-up 6m & F-up 12m & F-up 18m & F-up 24m & F-up 36m \\
\hline 1 & & 85 & 80 & 68 & 72 & 27 & 39 \\
2 & & 93 & 96 & 99 & 100 & 100 & 100 \\
3 & & 85 & 85 & 72 & 59 & 62 & DO $^{5}$ \\
4 & DO $^{1}$ & & & & & & \\
5 & & 60 & 59 & 65 & 50 & 45 & 20 \\
6 & & 87 & 90 & 98 & 94 & 95 & 95 \\
7 & & 59 & 51 & 80 & 90 & 97 & 84 \\
8 & & 1 & 12 & 15 & DO $^{4}$ & & \\
9 & & 24 & DO $^{3}$ & & & & \\
10 & & 48 & 30 & DO $^{3}$ & & & \\
11 & & 22 & 20 & 54 & 66 & DO $^{5}$ & \\
12 & & 51 & 56 & 80 & 54 & DO $^{6}$ & \\
13 & & 70 & 66 & 27 & DO $^{3}$ & & \\
14 & & 51 & 71 & 100 & 100 & 100 & \\
15 & & 41 & DO $^{3}$ & & & & \\
16 & & 7 & 77 & DO $^{3}$ & & & \\
17 & & 28 & 42 & 44 & 6 & -38 & \\
18 & DO $^{2}$ & & & & & & \\
19 & DO $^{1}$ & & & & & & \\
\hline
\end{tabular}

The numbers express the percentage in seizure reduction related to baseline.

F-up, follow-up; ${ }^{1}$, DO, drop out; , worsening; ${ }^{2}$, protocol violation; ${ }^{3}$, inefficacy; ${ }^{4}$, inefficacy/adverse experience; ${ }^{5}$, lost of follow up; ${ }^{6}$, subject choice. 
mother interrupted TPM treatment without our notice - and one (Case 19) due to increased seizure frequency. Seventeen patients initiated the extension phase but 3 patients (Cases 4, 9 and 15) droppedout during the beginning of the extension phase (visits 7,8 and 9) because worsening of the seizures (Case 4) and/or inefficacy of the treatment. Fourteen patients were evaluated at month 6 , and 7 patients were evaluated at month 36 . Reasons for 7 patients discontinue treatment during extension phase were: lack of efficacy, lost of follow-up, subject choice to try another treatment, and one patient (Case 8) for inefficacy and adverse experience (powder in the urine, which was interpreted as possible nephrolithiasis). None of these patients required hospitalization.

\section{Efficacy}

Table 3 shows efficacy results. At 36 months, seizure frequency was reduced $\geq 75 \%$ in 4 , and $<50 \%$ in 3 patients. Two children became seizure free for more than 24 months. Figure 1 shows the percentage of patients achieving at least $50 \%$ of seizure reduction according to seizure type at 6,12 and 24 months of follow-up. Our patient number 14 is currently in monotherapy with TPM. Patients who had best outcome achieved significant improvement 3 months after the introduction of TPM and before other drugs could be changed.

\section{Tolerability}

No significant clinical laboratory changes occurred, including other AED levels. No clinically significant treatment related changes were noted on physical or neurologic examinations or in electrocardiograms. Figure 2 shows the frequency of the most common side effects that occurred during the study. Most side effects were CNS related, with the most frequent being somnolence and anorexia. These were generally transient and tended to disappear with the continuation of the TPM treatment despite dosage increase (Fig 3).

Table 3. Number of patients who responded to TPM according to the percentage of response.

\begin{tabular}{ccccccc}
\hline Seizure frequency reduction & Month 3 & Month 6 & Month 12 & Month 18 & Month 24 & Month 36 \\
\hline$\geq 75 \%$ & 4 & 5 & 5 & 4 & 4 & 4 \\
$50-75 \%$ & 5 & 5 & 4 & 4 & 1 & 0 \\
$<50 \%$ & 7 & 4 & 3 & 1 & 3 & 3 \\
Number of patients & 16 & 14 & 12 & 9 & 8 & 7 \\
\hline
\end{tabular}

Table 4. Quality of life assessment. The numerals express the number of patients throughout the follow-up.

\begin{tabular}{lrrrrrrrrrrrrrrrrrrrrrrrr}
\hline \multicolumn{1}{c}{ Assessment } & \multicolumn{4}{c}{ Alertness } & \multicolumn{4}{c}{$\begin{array}{c}\text { Interaction with } \\
\text { environment }\end{array}$} & \multicolumn{4}{c}{$\begin{array}{c}\text { Daily } \\
\text { activities }\end{array}$} & \multicolumn{4}{c}{$\begin{array}{c}\text { Verbal } \\
\text { response }\end{array}$} \\
\hline Follow up(month): & 3 & 6 & 12 & 24 & 36 & 3 & 6 & 12 & 24 & 36 & 3 & 6 & 12 & 24 & 36 & 3 & 6 & 12 & 24 & 36 \\
6-Much worse & 0 & 0 & 0 & 0 & 0 & 0 & 1 & 0 & 1 & 1 & 0 & 0 & 0 & 0 & 0 & 0 & 0 & 0 & 0 & 0 \\
5-Worse & 0 & 0 & 0 & 1 & 1 & 0 & 1 & 2 & 0 & 0 & 0 & 0 & 0 & 0 & 0 & 0 & 0 & 0 & 0 & 1 \\
4-Unchanged & 12 & 10 & 8 & 5 & 4 & 9 & 5 & 2 & 1 & 1 & 11 & 7 & 6 & 2 & 2 & 10 & 6 & 5 & 1 & 0 \\
3-Improved & 1 & 1 & 0 & 0 & 0 & 3 & 3 & 4 & 2 & 2 & 3 & 4 & 3 & 2 & 3 & 4 & 6 & 5 & 6 & 2 \\
2-Much improved & 3 & 2 & 4 & 2 & 2 & 4 & 3 & 4 & 4 & 3 & 2 & 2 & 3 & 4 & 2 & 2 & 1 & 2 & 1 & 3 \\
1-Very much improved & 0 & 1 & 0 & 0 & 0 & 0 & 1 & 0 & 0 & 0 & 0 & 1 & 0 & 0 & 0 & 0 & 1 & 0 & 0 & 1 \\
\hline
\end{tabular}




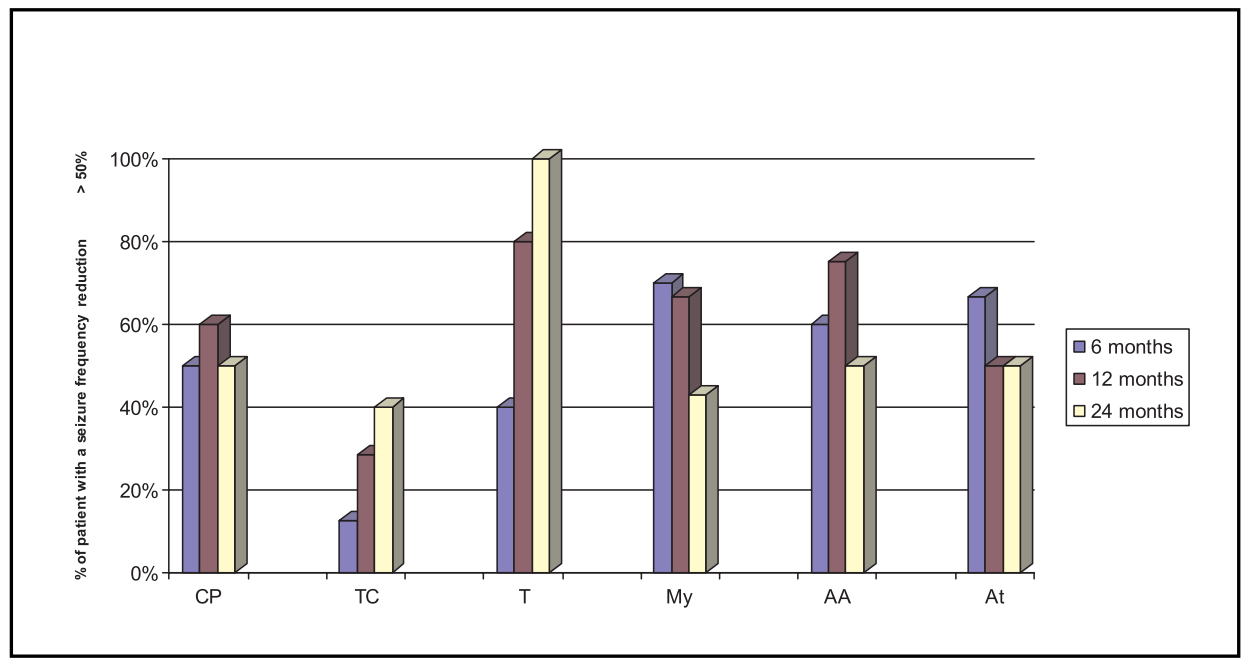

Fig 1. This figure shows the percentage of patients achieving at least $50 \%$ of seizure reduction according to the seizure type at 6, 12 and 24 months of follow-up.

Powder in the urine (1 patient) was the only adverse experience in the long-term phase and did not require hospitalization.

\section{Quality of life}

Table 4 shows the total number of the patients according to the pontuation at $3(n=16), 6$ $(\mathrm{n}=14), 12(\mathrm{n}=12), 24(\mathrm{n}=8)$ and $36(\mathrm{n}=7)$ months of TPM treatment. As far as alertness is concerned we can verify that at 36 months of treatment, one patient was worse, 4 were unchanged and 2 improved. After 36 months of TPM treatment 5 patients were interacting better with environment, 5 were more active and independent and 6 had their verbal performance improved.

Statistical analysis was not performed due to the small sample size.

\section{DISCUSSION}

Our results indicate that TPM may be effective in the treatment of LGS. Four of our patients (21\%) had more than $75 \%$ of improvement and 2 of them were seizure free for more than 2 years of follow-up. They achieved significant improvement soon after TPM was introduced and before other drug dosages could be changed. Felbamate was approved in the United States for use in LGS based on the findings of $34 \%$ decrease in the frequency of atonic seizures and $19 \%$ decrease in the total frequency of seizures ${ }^{13}$. In that study, 5 patients $(13 \%)$ had no seizures during the maintenance period, which lasted 56 days. Longer periods of follow-up are necessary to evaluate the true efficacy as some patients who present a favorable response in the beginning of the treatment may fail to respond to the medication later on. Four of our patients (Cases 1, 5, 16 and 17) have not sustained the improvement that they achieved at 6 months. On the other hand, the two seizure free patients in the present study (Cases 2 and 14) achieved the maximum response after 12 months of treatment. These data reinforce the importance of a long-term follow-up to evaluate drug efficacy.

Lamotrigine (LTG) has been found to be another option in the treatment of patients with LGS $^{14,15}$. Sixteen and 10 LGS patients, respectively, were submitted to treatment with LTG and the efficacy found in those studies is comparable to our findings. However, LTG discontinuation was not infrequent due to the occurrence of skin rash, particularly in patients with valproate (VPA) comedication. This may limit the association of VPA and LTG in some patients. None of our children 


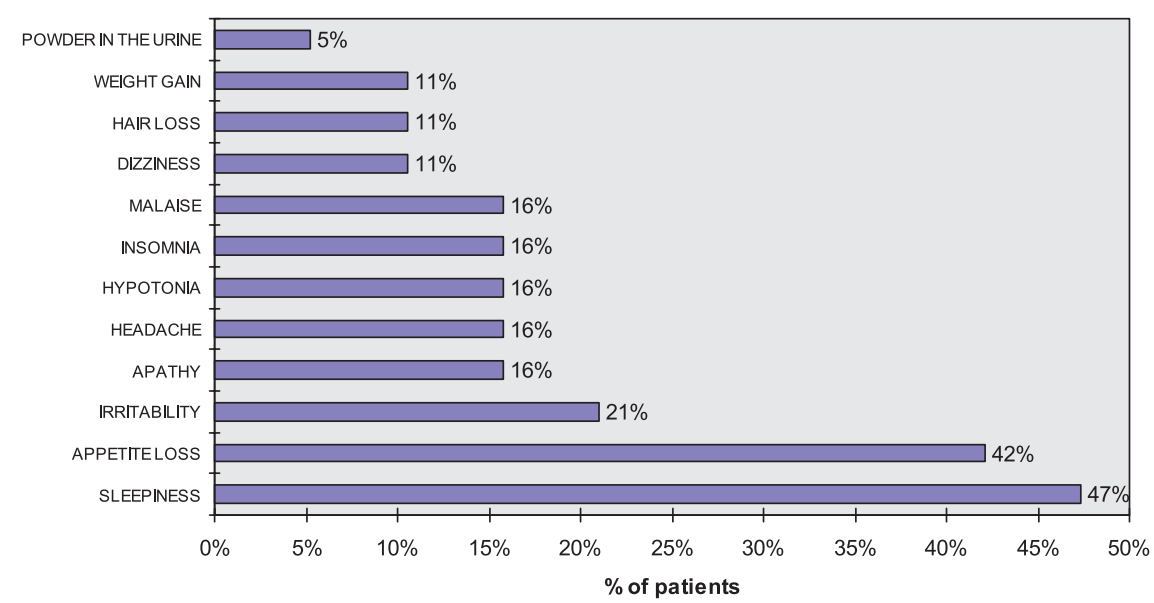

Fig 2. This figure shows the frequency of the most common side effects that occurred during the study.

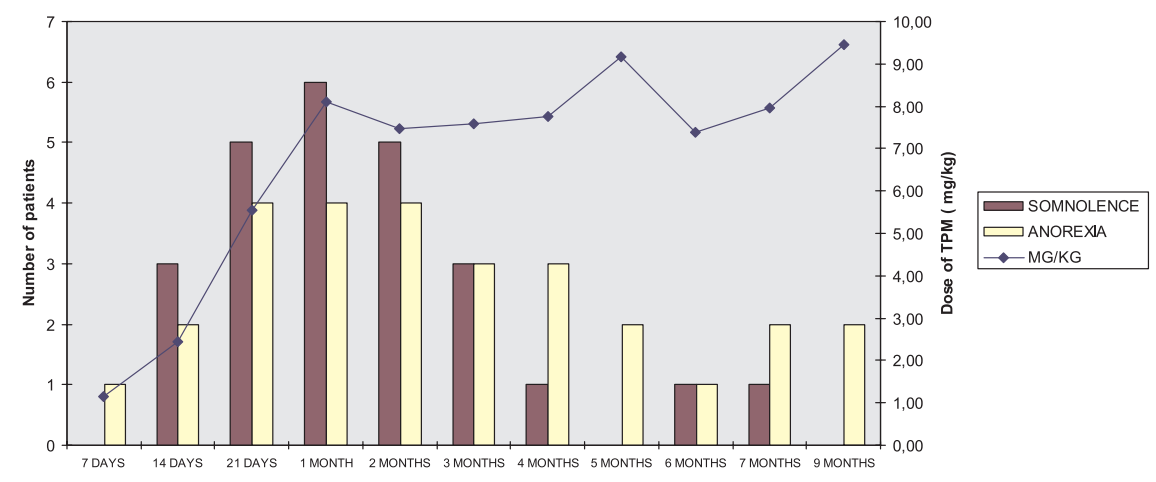

Fig 3. Somnolence and anorexia, the most frequent side effects, tended to disappear with the continuation of the TPM treatment despite dosage increase.

had rash and this side effect seems not to be a problem with TPM, which may suggest that TPM can be added to VPA without main concern.

As it is shown in Figure 1, best response to TPM at 24 months of treatment was obtained in tonic seizures, followed by atonic, atypical absence, complex partial, myoclonic and tonic clonic seizures. Sachdeo et al. ${ }^{16}$ treated 16 patients with LGS and found better response to TPM in generalized tonic-clonic seizures. Glauser ${ }^{17}$ presented the results of 18 LGS patients treated with TPM and better response occurred in tonic-atonic seizures. Neither our study nor theirs had patients enough to conclude which type of seizure responds better to TPM.

TPM has a relatively low propensity for clinically significant drug interactions, and its pharmacokinetic and drug interaction profiles represent a clear advance over the traditional $\mathrm{AEDs}^{6,9}$. The half-life of TPM as monotherapy is sufficiently long and consistent to allow once or at most twice- 
daily dosing. Renal excretion is the major route of elimination of TPM ${ }^{9}$. Previous observations indicate no significant changes in plasma levels of traditional AEDs when TPM is added ${ }^{6}$. Our results support these findings, as there were no major changes in plasma levels of other AEDs in this study.

Most adverse events observed during TPM add-on therapy are CNS related ${ }^{18-22}$. In a review of 1,809 individuals treated with TPM, Shorvon ${ }^{22}$ found dizziness and fatigue as the most common side effects. Our cognitively impaired children could not complain of dizziness or fatigue. We found somnolence and anorexia as the most frequent adverse events in our patients. Some of them presented anorexia but no weight loss, which could be of concern in children. Weight loss with TPM is infrequently a limiting factor during treatment and tends to plateau during long-term therapy ${ }^{22}$. As is shown in Figure 3, somnolence and anorexia tended to subside as the study continued despite the increasing of TPM dosage.

There is a small but definite increased risk for nephrolithiasis with TPM, which was observed in $1.5 \%$ of the patients ${ }^{22}$. None of the stones required open surgery, and three-fourths were passed spontaneously. One of our patients possibly has had nephrolithiasis and we interrupted TPM treatment. His follow-up showed spontaneous resolution of this effect. The absence to date of any clinically important changes in laboratory parameters of tests of neurologic or special sense function is most encouraging.

According to our QL questionnaires approximately one third of our patients had their QL improved after TPM treatment. We considered this finding an important one due to the poor QL profile of LGS patients.

It has been important to find new options in the treatment for such a devastating epileptic condition in order to alleviate the symptoms and improve the QL of those patients. It is for such patients that new AEDs are required ${ }^{23}$.

We still can not give the final word about TPM in LGS because of the small number of patients but we found encouraging results which suggest we should continue pursuing this treatment.

We conclude that TPM may be useful as adjunctive therapy in the treatment of LGS. We found that the efficacy of TPM was maintained in long-term treatment in more than $40 \%$ of patients and that long-term safety was confirmed. Most adverse events were CNS related and tended to subside as the treatment continued. Our results should be reinforced by controlled studies with a larger number of patients.

Acknowledgements - The authors thank Dr. Fernando Cendes for reviewing the manuscript.

\section{REFERENCES}

1. Brown SD, Wolf HH, Swinyard EA, Twyman RE, White HS. The novel anticonvulsant topiramate enhances GABAmediated chloride flux (Abstract). Epilepsia 1993;34(Suppl 2):122.

2. Coulter DA, Sombati S, De Lorenzo RJ. Selective effects of topiramate on sustained repetitive firing and spontaneous bursting in hippocampal neurons (Abstract). Epilepsia 1993;34(Suppl 2):123.

3. Cendes F, Ragazzo PC, Costa V, Martins LF. Corpus callosotomy in treatment of medically resistant epilepsy: preliminary results in a pediatric population. Epilepsia 1993;34:910-917.

4. Farrel K. Symptomatic generalized epilepsy and Lennox-Gastaut syndrome. In Wyllie E (ed). The treatment of epilepsy: principles and practice. Baltimore: Williams \& Wilkins, 1997:530-539.

5. Faught E. Felbamate. In Wyllie E (ed). The treatment of epilepsy: principles and practice. Baltimore: Williams \& Wilkins, 1997:913-919.

6. Bourgeois BFD. Drug interaction profile of topiramate. Epilepsia 1996;37(Suppl 2):S14-S17.

7. Leppik IE. Antiepileptic drugs in development: prospects for the near future. Epilepsia 1994;35(Suppl 4):S29-S40.

8. Sachdeo RC, Sachdeo SK, Walker SA, Kramer LD, Nayak RK, Doose DR. Steady-state pharmacokinetics of topiramate and carbamazepine in patients with epilepsy during monotherapy and concomitant therapy. Epilepsia 1996;37:774-780.

9. Perucca E. Pharmacokinetic profile of topiramate in comparison with other new antiepileptic drugs. Epilepsia 1996;37 (Suppl 2):S8-S13.

10. Commission on Classification and Terminology of the International League Against Epilepsy. Proposal for revised classification of epilepsies and epileptic syndromes. Epilepsia 1989;30:389-399.

11. Gastaut H, Roger J, Soulayrol R, Tassinari CA, Regis H, Dravet C. Childhood epileptic encephalopathy with diffuse slow spike-waves (otherwise known as "petit mal variant") or Lennox syndrome. Epilepsia 1966;7:139-179. 
12. Aicardi J. Lennox-Gastaut syndrome and myoclonic epilepsies of infancy and early childhood. In Aicardi J (ed). Epilepsy in children. New York: Raven Press, 1986:39-65.

13. The Felbamate Study Group in Lennox-Gastaut Syndrome. Efficacy of felbamate in childhood epileptic encephalopathy (Lennox-Gastaut syndrome). N Engl J Med 1993; 328:29-33.

14. Donaldson JA, Glauser TA, Olberding LS. Lamotrigine adjunctive therapy in childhood epileptic encephalopathy (the Lennox Gastaut syndrome). Epilepsia 1997;38:68-73.

15. Schlumberger E, Chavez F, Palacios L, Rey E, Pajot N, Dulac O. Lamotrigine in treatment of 120 children with epilepsy. Epilepsia 1994;35:359-367.

16. Sachdeo R, Kugler S, Wenger E, Mandelbaum D. Topiramate in Lennox-Gastaut syndrome (Abstract). Epilepsia 1996;37(Suppl 4):118.

17. Glauser TA. Preliminary observations on topiramate in pediatric epilepsies. Epilepsia 1997;38(Suppl 1):S37-S41.

18. Ben-Menachem E, Henriksen O, Dam M, et al.. Double-blind, placebo-controlled trial of topiramate as add-on therapy in patients with refractory partial seizures. Epilepsia 1996;37:539-543.

19. Chadwick DW, Marson T, Kadir Z. Clinical administration of new antiepileptic drugs: an overview of safety and efficacy. Epilepsia 1996;37(Suppl 6):S17-S22.

20. Faught E, Wilder BJ, Ramsay RE, et al., and the Topiramate YD Study Group. Topiramate placebo-controlled dose-ranging trial in refractory partial epilepsy using 200-, 400-, and 600-mg daily dosages. Neurology 1996;46:1684-1690.

21. Privitera M, Fincham R, Penry J, et al., and the Topiramate YE Study Group. Topiramate placebo-controlled dose-ranging trial in refractory partial epilepsy using 600-, 800-, and 1,000-mg daily dosages. Neurology 1996;46:1678-1683.

22. Shorvon SD. Safety of topiramate: adverse events and relationships to dosing. Epilepsia 1996;37(Suppl 2):S18-S22.

23. Shorvon SD. The epidemiology and treatment of chronic and refractory epilepsy. Epilepsia 1996;37(Suppl 2):S1-S3. 